\title{
Angiotensin-converting enzyme single nucleotide polymorphism is a genetic risk factor for cardiovascular disease: a cohort study of hypertensive patients
}

\author{
Nozomi Kato, Yuji Tatara, Mitsuru Ohishi, Yasushi Takeya, Miyuki Onishi, Yoshihiro Maekawa \\ and Hiromi Rakugi
}

The renin-angiotensin system (RAS) adversely affects stroke and cardiovascular disease; polymorphisms in genes involved in this system are associated with cardiovascular disease. The aim of the present study was to confirm the genetic risk of these polymorphisms for stroke and cardiovascular events in a cohort study of $\mathbf{5 1 5}$ hypertensive patients in Japan (follow-up period $90.6 \pm 30.2$ months). The insertion/deletion (I/D) polymorphism of the gene encoding angiotensin-converting enzyme (ACE), the M235T amino acid change in angiotensinogen, and the $\mathrm{A1166C}$ polymorphism in angiotensin II type 1 receptor were determined by TaqMan PCR. In Kaplan-Meier analyses, the ACE I/D polymorphism was a risk factor for cerebro-cardiovascular events, especially cardiovascular events $(P<0.0001)$, and the M235T mutation was a risk factor for cardiovascular events $(P<0.0105)$. The cumulative rates of cerebro-cardiovascular end points for the $A C E$ polymorphism were $10.6,16.4$ and $42.2 \%$ for the II ( $n=207)$, ID $(n=244)$ and DD $(n=64)$ genotype carriers, respectively $(P<0.0001)$. Cox's proportional hazard models revealed that the $A C E$ DD genotype was a risk factor for cerebro-cardiovascular and cardiovascular events (after adjusting for common risk factors), anti-hypertensive treatment and RAS inhibition $(P<0.0001)$. Moreover, after adjustment for the common risk factors left ventricular hypertrophy and previous myocardial infarction/stroke, these phenomena were preserved. Thus, the DD genotype of $A C E$ may be a genetic risk factor for cerebro-cardiovascular disease, especially cardiovascular events, in hypertensive patients in Japan.

Hypertension Research (2011) 34, 728-734; doi:10.1038/hr.2011.28; published online 17 March 2011

Keywords: cardiovascular disease; gene polymorphism; renin-angiotensin system; the gene ACEI/D polymorphism

\section{INTRODUCTION}

Hypertension is a common disorder associated with increased cerebro-cardiovascular disease (CVD) and a leading cause of morbidity and mortality worldwide. ${ }^{1} \mathrm{~A}$ complex interaction of genetic and environmental factors influences CVD. ${ }^{2}$ Many reports suggest that the renin-angiotensin system (RAS) has an important role in the development of CVD, including contributions from the vasoactive peptide angiotensin II-produced from angiotensinogen (AGT) by renin and angiotensin-converting enzyme (ACE) - and its receptor, angiotensin II type 1 receptor (AT1R). ${ }^{3-5}$ RAS-component gene polymorphisms such as the M235T single nucleotide polymorphism (SNP) in AGT, the insertion (I)/deletion (D) polymorphisms in ACE, and the A1166C SNP in AT1R have been reported from various laboratories, including our group. Subjects with the TT AGT genotype have 10-20\% higher plasma AGT concentrations, ${ }^{6}$ and subjects with the ACE D allele exhibit higher levels of serum and tissue ACE.,8

In 1992, the Etude Cas-Temoin de l'Infarctus du Myocarde study demonstrated that subjects with the DD genotype carry a significantly increased risk of myocardial infarction (MI). ${ }^{9}$ We reported that subjects with the DD genotype have a higher risk of restenosis after emergency percutaneous coronary transluminal angioplasity, ${ }^{10}$ hypertension in males ${ }^{11}$ and stroke. ${ }^{12}$ We also reported that subjects with the AGT TT genotype are at higher risk for lacunar infarction ${ }^{13}$ and history of hypertension, ${ }^{14}$ but not stroke. ${ }^{12}$ Indeed, the literature contains many reports from other laboratories about these genotypes and cardiovascular disease, but many of these results remain controversial.

A cohort investigation with hypertensive patients could help clarify the genetic risk of RAS polymorphisms for CVD. The GenHAT study, a sub-analysis of the ALLHAT study, reported that the ACE I/D polymorphism conferred no genetic risk for cardiovascular diseases: ${ }^{15}$ however, the genetic frequencies of the ACE I/D polymorphism are quite different, and a cohort study of hypertensive patients in Japan was not reported. Here, we investigate whether three RAS genotypes interact with the risk of CVD in hypertensive patients in Japan. 


\section{METHODS}

Study design and population

This cohort study was designed as a part of the NOn-invasive Atherosclerotic evaluation in Hypertension study. ${ }^{16}$ At Osaka University Hospital, a total of 705 serial outpatients who had been diagnosed with essential hypertension were recruited between January 1998 and June 2004. A total of 548 subjects were genotyped for the three polymorphisms (II, ID, DD). A clinical survey of each patient was conducted, but we were unable to obtain sufficient information regarding cardiovascular events and/or mortality from 33 patients, leaving 515 hypertensive patients available for analysis. Hypertension was defined as systolic blood pressure $\geqslant 140 \mathrm{~mm} \mathrm{Hg}$, diastolic blood pressure $\geqslant 90 \mathrm{~mm} \mathrm{Hg}$, and/or the use of antihypertensive medication. The study protocol was approved by the hospital ethics committee and written informed consent was obtained from all participants. At entry, a total of 276 patients were not receiving treatment with any antihypertensive drug, and 239 patients were treated with one or more antihypertensive drugs as follows: 167 patients with a calcium antagonist, 145 patients with an angiotensin receptor blocker (ARB) and/or with an ACE inhibitor (ACE-I), 50 patients with a $\beta$-blocker, 31 patients with a diuretic and 12 patients with an $\alpha$-blocker.

\section{Follow-up evaluation}

Clinical follow-up was conducted by clinical visits, mailed questionnaires and telephone contact every year. The questionnaire included the events of hypertensive complications described below or cause of death; we confirmed the responses in detail by comparing them against patient medical sheets. The primary endpoint of this study was a new onset of CVD, such as stroke, angina pectoris, MI, or heart failure. Specialists diagnosed stroke as a neurological disturbance for at least $24 \mathrm{~h}$ and evidence of infarction or bleeding using computed tomography or magnetic resonance imaging. Angina was diagnosed as typical chest pain without elevated levels of creatinine kinase and positive ST change on a stress ECG, and MI as typical chest pain with a more than twofold above normal level of creatinine kinase release and positive ST change on an ECG. Heart failure was diagnosed using American Heart Association criteria. ${ }^{16}$ The follow-up duration encompassed the interval from the initial evaluation to the time of event onset or the end of 2009. The average follow-up period \pm s.d. was $90.6 \pm 30.2$ months.

\section{Genotyping}

Peripheral venous blood was drawn into pyrogen-free tubes with ethylenediaminetetraacetic acid, then placed on melting ice and centrifuged for $15 \mathrm{~min}$ at $1500 \times g$ for $10 \mathrm{~min}$ at $4{ }^{\circ} \mathrm{C}$. Plasma was stored at $-80^{\circ} \mathrm{C}$, and samples were thawed only once. The conventional genotyping method for screening ACE I/D polymorphisms consists of two steps: a TaqMan PCR and agarose gel electrophoresis. In the present study, we prepared a C allele-specific probe, $5^{\prime}$-FamTGACCTCGTGATCCG-3' ${ }^{\prime}$, and a T allele-specific probe, $5^{\prime}$-Vic-CAGGTCTAG AGAAATG- $3^{\prime}$. We prepared three primers with the ACE sequences: forward, 5'-CAGTAAGCCACTGCTGGAGACC- ${ }^{\prime}$ and 5'-TTAGCCGGGATGGTCTCGAT-3'; and reverse, 5'-GGCGAAACCACATAAAAGTGACTG-3'. Cycling conditions were an initial denaturation at $95^{\circ} \mathrm{C}$ for $10 \mathrm{~min}$ followed by 45 cycles of $30 \mathrm{~s}$ at $95^{\circ} \mathrm{C}, 60 \mathrm{~s}$ at $59^{\circ} \mathrm{C}$ and $60 \mathrm{~s}$ at $72^{\circ} \mathrm{C}$. The resulting PCR products were separated on $1.5 \%$ agarose gels, stained with ethidium bromide and visualized under ultraviolet light. AGT polymorphisms encoding the M235T amino acid substitution, as well as the $A T 1 R$ polymorphism1166A/C, were determined by amplification with biotinylated primers and hybridization to immobilized sequence-specific oligonucleotides as previously described. ${ }^{17}$

\section{Confounding factors}

To clarify the influence of other risk factors on event-free survival for CVD and cardiovascular disease, we estimated four Cox proportional hazard models (Table 3). As arterial stiffness measured by pulse wave velocity was an independent risk factor for the occurrence of $\mathrm{CVD}^{16}$ in the NOn-invasive Atherosclerotic evaluation in Hypertension study, we included pulse wave velocity as a confounding CVD risk factor in addition to age, gender, smoking status, systolic blood pressure, diastolic blood pressure, diabetes mellitus and dyslipidemia in Model 2. To exclude the influences of antihypertensive drugs, we adjusted for CVD risk factors and administration of antihypertensive drugs in Model 3. Our assumption that ACE-Is and/or ARBs impacted the influence of these SNPs has been demonstrated previously; ${ }^{18}$ therefore, we also adjusted for CVD risk factors, ACE-I administration, and/or ARB administration in Model 4. To evaluate the influence of high-risk patients included in GenHAT, ${ }^{15}$ we selected advanced CVD risk factors such as left ventricular hypertrophy shown on ECG or echocardiography, and previous MI and stroke (Table 3b).

\section{Statistical analysis}

Statistical analysis was performed with analysis of variance and Student's $t$-test. An event-free curve was estimated using the Kaplan-Meier method. We used a log-rank test and non-adjusted Cox proportional hazard models to evaluate the relative risk and 95\% confidence intervals. Baseline clinical variables for these patients were analyzed with the Cox proportional hazard model after adjusting for confounding factors, and the hazard ratio with 95\% confidence intervals was given for each factor. Analyses were performed with commercially available software (JMP ver. 8; SAS Inc., Cary, NC, USA). A value of $P<0.05$ was considered statistically significant.

\section{RESULTS \\ Kaplan-Meier survival curves according to $A G T, A C E$ I/D and AT1R polymorphisms}

The observed frequencies of the RAS polymorphisms were in HardyWeinberg equilibrium (Table 1). Kaplan-Meier analysis indicated a significant difference in the incidence of CVD according to the $A C E$ I/D polymorphism $(P<0.0001)$, but not according to the $A G T$ or $A T 1 R$ polymorphisms (Figure 1). The AGT polymorphism exhibited a statistically significant difference in cardiovascular events in the Kaplan-Meier survival analysis ( $P=0.0105$; data not shown). When we performed a Kaplan-Meier analysis classified into a dominant or recessive model group, the TT genotype of $A G T$ showed a significantly higher incidence of cardiovascular diseases $(P=0.0026)$ and a trend towards a higher incidence of CVD $(P=0.0808)$ than the MM+MT genotype determined from the AGT and AT1R genotypes.

\section{Baseline characteristics}

Our study focused on the ACE I/D polymorphism, and we detected significant differences in diastolic blood pressure and incidence of diabetes among the three genotypes (Table 2a). To clarify the influence of genetic background on the risk of CVD events, we also analyzed the relationship between CVD events and $A C E$ genotype in patients aged $<65$ years $(n=298$; Table $2 \mathrm{~b}$ ); no significant difference in baseline clinical variables was uncovered in this sub-group.

\section{Clinical outcomes}

The cumulative rates of CVD end points were 10.6\% ( $n=22), 16.4 \%$ $(n=40)$ and $42.2 \% \quad(n=27)$ in subjects with the II $(n=207)$, ID $(n=244)$ and DD genotypes $(n=64)$, respectively $(P<0.0001)$. There was a significant difference in CVD incidence in subjects with ACE polymorphisms (DD vs. ID and II; $P<0.0001$; Figure 2), especially for cardiovascular disease, in the Kaplan-Meier survival curves. The Cox proportional hazard model indicated that the DD genotype was an independent risk factor for CVD and cardiovascular

Table 1 Hardy-Weinberg equilibrium of the genotypes detected in this study

\begin{tabular}{lcccc}
\hline & \multicolumn{2}{c}{ Genotype } & \multicolumn{2}{c}{ Allele frequency } \\
\hline ACE I/D & II/ID/DD & $207 / 244 / 64$ & I/D & $63.9 / 36.1 \%$ \\
M235T & MM/MT/TT & $354 / 141 / 20$ & M/T & $82.4 / 17.6 \%$ \\
A1166C & AA/AC/CC & $438 / 70 / 7$ & A/C & $91.8 / 8.2 \%$ \\
\hline
\end{tabular}


diseases, both without adjustment and after adjustment (Table 3a) for CVD risk factors $(P<0.0001)$. The analysis adjusted for advanced CVD risk factors is shown in Table $3 b$. In this model, we found that the DD genotype was an independent risk factor for CVD and cardiovascular diseases, both without adjustment and with adjustment for advanced CVD risk factors. Moreover, we also found that the DD genotype was an independent low-risk factor for stroke after adjustment for advanced CVD risk factors $(P=0.0476)$.

\section{Clinical outcomes and antihypertensive treatment}

Realizing that CVD events are reduced by anti-hypertensive treatment, we evaluated the Cox proportional hazard model after adjustment for CVD risk factors and antihypertensive treatment in Model 3 (Tables $3 \mathrm{a}$ and $3 \mathrm{~b}$ ). The DD genotype was an independent risk factor for CVD and cardiovascular diseases after adjustment for anti-hypertensive treatment and CVD risk factors (Table 3a; $P<0.0001$ ) or advanced CVD risk factors (Table $3 \mathrm{~b} ; P<0.0001$ ). The DD genotype trended toward being an independent risk factor for stroke, but was not statistically significant after adjusting for advanced CVD risk factors and anti-hypertensive treatment (Table 3b; $P=0.0537$ ). In Model 4, we excluded the influence of RAS inhibition by adjusting for CVD risk factors and treatment with ACE-Is and/or ARBs (Table 3a), and advanced CVD risk factors and treatment with ACE-Is and/or ARBs (Table 3b). The DD genotype was an independent risk factor for CVD and cardiovascular diseases after adjusting for ACE-I and/or ARB treatment (Tables $3 \mathrm{a}$ and $3 \mathrm{~b} ; P<0.0001$ ). The DD genotype trended towards being an independent low-risk factor for stroke in Model 4, but was not statistically significant after adjusting for advanced CVD risk factors and treatment with ACE-Is and/or ARB (Table 3b; $P=0.0552)$.

\section{Clinical outcomes in patients under 65 years of age}

To emphasize the genetic influences of $A C E$ polymorphisms on the occurrence of CVD, we performed a sub-analysis in patients under a

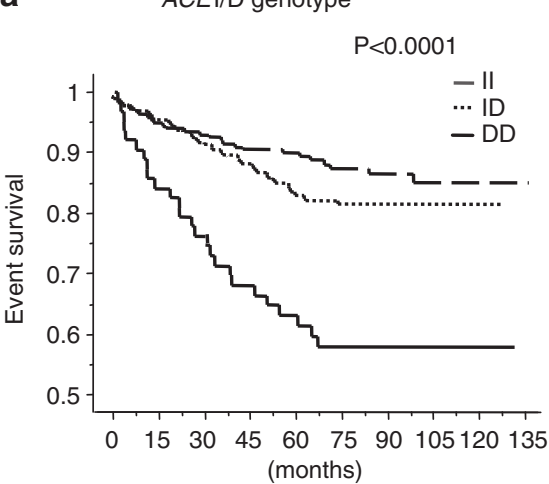

b

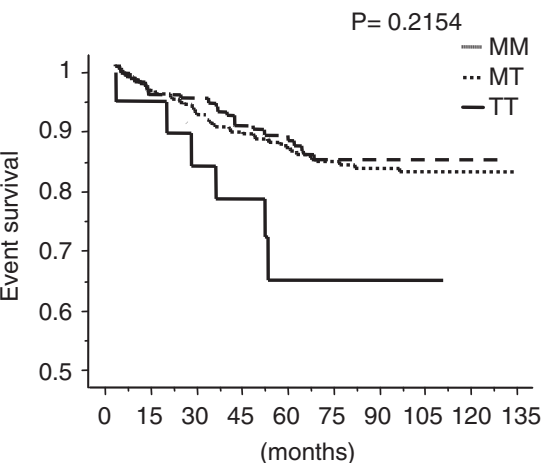

C ATIR genotype

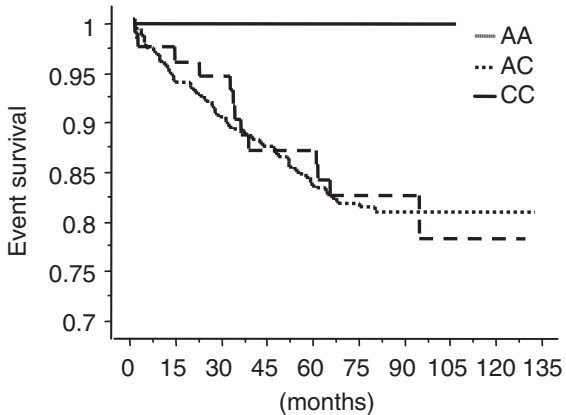

Figure 1 Kaplan-Meier analysis of cerebro-cardiovascular disease according to polymorphisms in renin-angiotensin system genes. (a) Effect of angiotensinconverting enzyme (ACE) insertion (I) or deletion (D) genotypes. (b) Effect of the M235T mutation in angiotensinogen (AGT). (c) The effect of the A1166C polymorphism in the angiotensin II type 1 receptor (AT1R) gene.

Table 2a Patient characteristics and the ACE polymorphisms at baseline in all patients

\begin{tabular}{|c|c|c|c|c|c|}
\hline & $I I, I D, D D(515)$ & // (207) & ID (244) & $D D(64)$ & P-value \\
\hline Male gender (\%) & 57.1 & 54.1 & 59.8 & 56.3 & 0.4671 \\
\hline $\mathrm{DBP}(\mathrm{mm} \mathrm{Hg})$ & $82.0 \pm 12.4$ & $81.1 \pm 11.6$ & $83.3 \pm 13.0$ & $79.5 \pm 12.6$ & 0.0457 \\
\hline $\mathrm{HR}(\mathrm{bpm})$ & $67.8 \pm 11.0$ & $66.5 \pm 11.2$ & $68.8 \pm 10.7$ & $68.1 \pm 10.9$ & 0.1254 \\
\hline PWV ( \pm s.d.) & $9.09 \pm 4.75$ & $8.75 \pm 1.60$ & $9.30 \pm 6.70$ & $9.38 \pm 1.79$ & 0.4358 \\
\hline Previous MI (\%) & 4.5 & 2.90 & 4.92 & 7.81 & 0.2402 \\
\hline Previous stroke (\%) & 7.6 & 6.76 & 7.79 & 9.38 & 0.7811 \\
\hline LVH (\%) & 23.7 & 28.02 & 20.83 & 22.22 & 0.3384 \\
\hline Antihypertensive drugs (\%) & 77.3 & 77.8 & 77.9 & 79.7 & 0.9438 \\
\hline ACE-I/ARB (\%) & 50.1 & 51.2 & 49.2 & 50.0 & 0.9119 \\
\hline CCB (\%) & 38.4 & 39.6 & 36.1 & 39.1 & 0.7246 \\
\hline
\end{tabular}

Abbreviations: ACE-I, angiotensin-converting enzyme inhibitor; ARB, angiotensin II receptor blocker; CCB, calcium channel blocker; DBP, diastolic blood pressure; DL, dyslipidemia; HR, heart rate; LVH, left ventricular hypertrophy; MI, myocardial infarction; PWV, pulse wave velocity; SBP, systolic blood pressure. 
Table $2 \mathrm{~b}$ Patient characteristics and the ACE polymorphisms at baseline in all subgroup of patients under 65 years of age

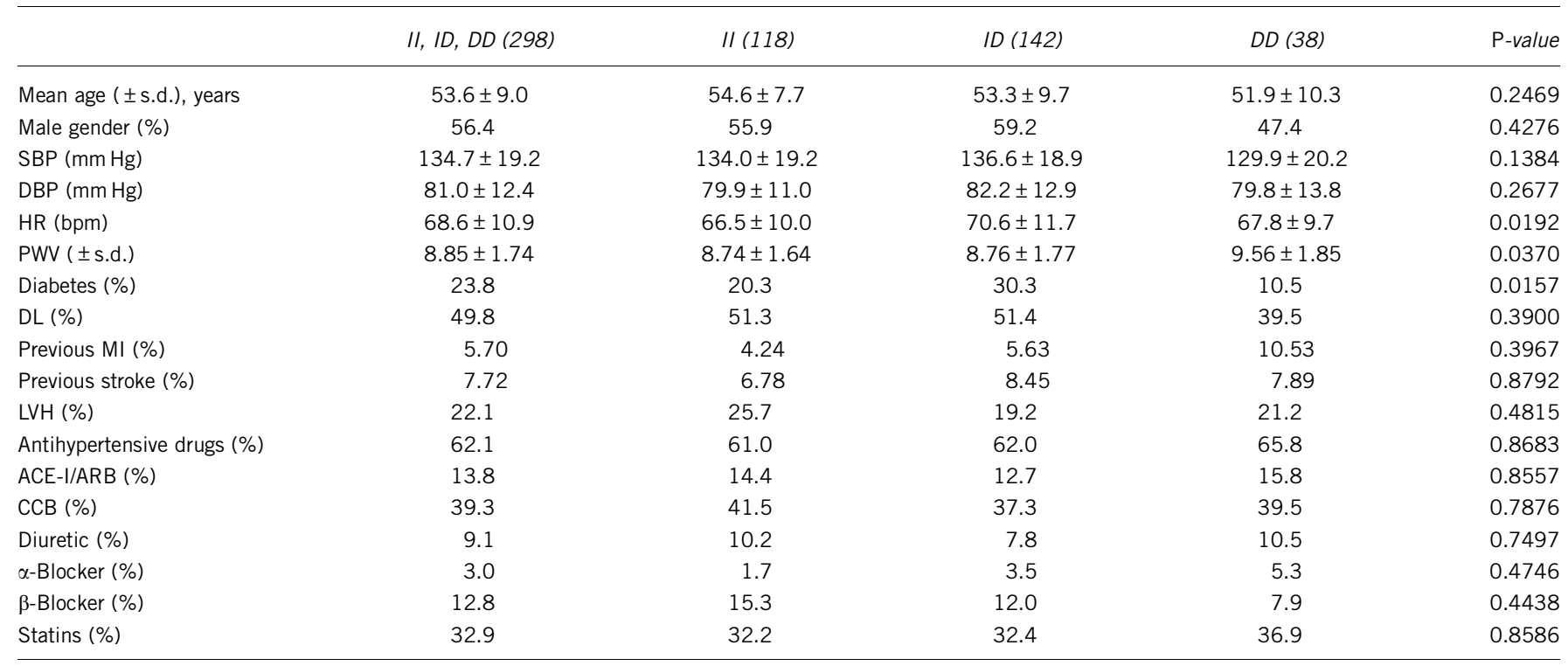

Abbreviations: ACE-I, angiotensin-converting enzyme inhibitor; ARB, angiotensin II receptor blocker; CCB, calcium channel blocker; DBP, diastolic blood pressure; DL, dyslipidemia; HR, heart rate; LVH, left ventricular hypertrophy; MI, myocardial infarction; PWV, pulse wave velocity; SBP, systolic blood pressure.
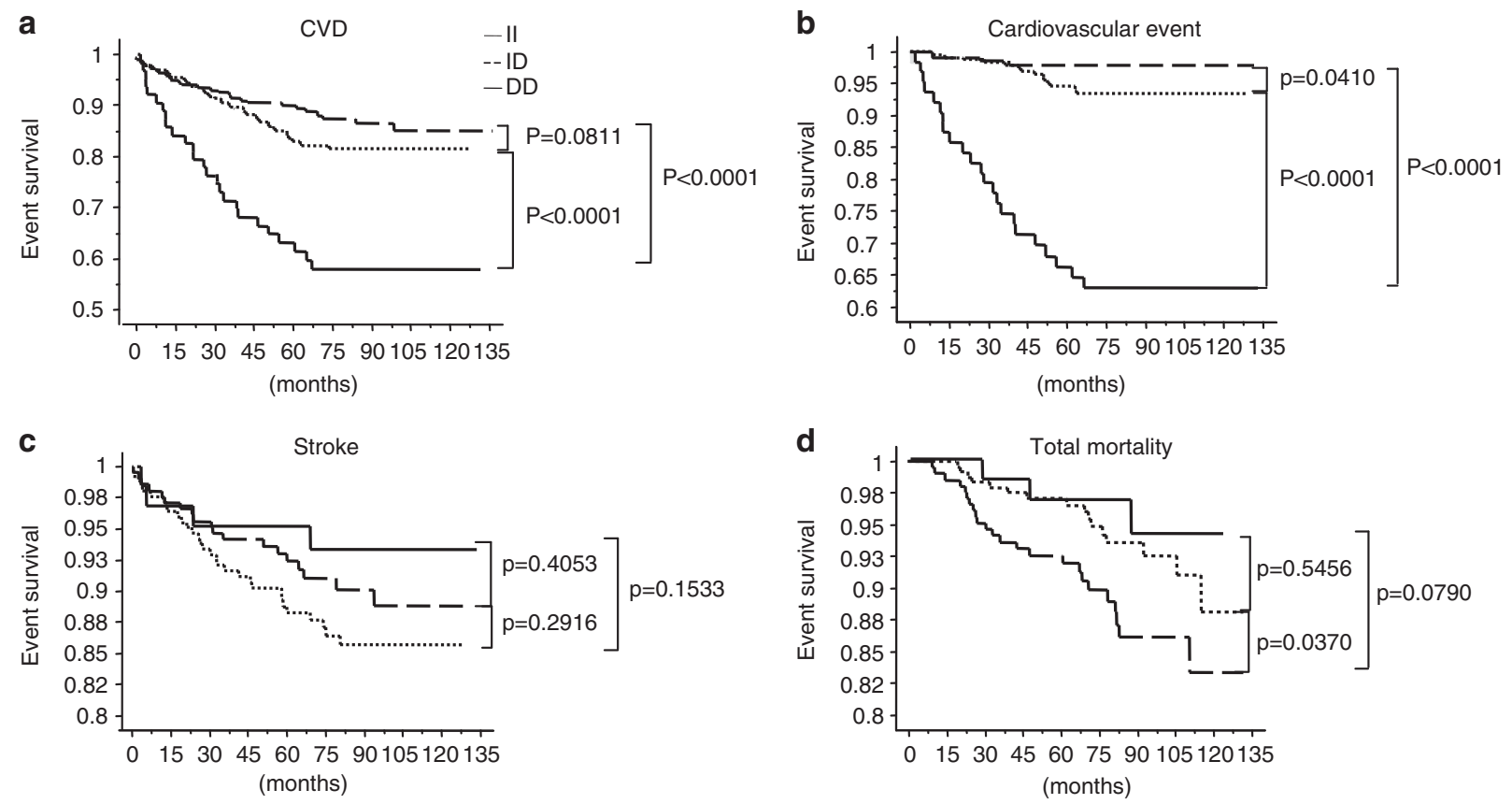

Figure 2 Kaplan-Meier analysis for cumulative primary end points according to the ACE insertion (I) or deletion (D) genotype. (a) CVD, cerebrocardiovascular disease; (b) cardiovascular event; (c) stroke; (d) total mortality.

65 years of age (Tables $3 c$ and $3 d$ ). The DD genotype was an independent risk factor for CVD and cardiovascular diseases after adjustment for anti-hypertensive treatment and CVD risk factors (Table 3c; $P<0.0001$ ) or advanced CVD risk factors (Table 3 b; $P<0.005$ ) in these patients.

\section{DISCUSSION}

Although several previous studies have investigated the associations among polymorphisms in the RAS genes and CVD, to our knowledge this is the first study to investigate the associations among the RAS polymorphisms and CVD using a hospital-based cohort study of hypertensive patients in Japan. In this prospective cohort of 515 hypertensive patients, we demonstrated the deleterious effects of the $\mathrm{D}$ allele of the ACE I/D polymorphism on CVD, especially regarding cardiovascular disease. Moreover, we detected no association between the AT1R polymorphism and CVD events; however, the AGT polymorphism appeared to have an influence on the incidence of cardiovascular diseases in a Kaplan-Meier analysis. 
Table 3a Cox proportional hazard models for all patients

\begin{tabular}{|c|c|c|c|c|c|c|c|c|}
\hline & \multicolumn{2}{|l|}{$\begin{array}{c}\text { Model } 1 \\
\text { (not adjusted) }\end{array}$} & \multicolumn{2}{|c|}{$\begin{array}{c}\text { Model } 2 \text { (adjusted for } \\
\text { CVD risk factors) }\end{array}$} & \multicolumn{2}{|c|}{$\begin{array}{l}\text { Model } 3 \text { (model } 2 \text { adjusted } \\
\text { for antihypertensive drugs) }\end{array}$} & \multicolumn{2}{|c|}{$\begin{array}{l}\text { Model } 4 \text { (model } 2 \text { adjusted } \\
\text { for } A C E-I \text { or/and } A R B \text { ) }\end{array}$} \\
\hline & $\operatorname{Exp}(95 \% \mathrm{Cl})$ & $\mathrm{P}$ & $\operatorname{Exp}(95 \% \mathrm{Cl})$ & $\mathrm{P}$ & $\operatorname{Exp}(95 \% \mathrm{Cl})$ & $\mathrm{P}$ & $\operatorname{Exp}(95 \% \mathrm{Cl})$ & $\mathrm{P}$ \\
\hline CVD II, ID vs DD & $3.643(2.317-5.727)$ & $<0.0001$ & $3.532(2.193-5.688)$ & $<0.0001$ & $3.601(2.231-5.811)$ & $<0.0001$ & $3.692(2.307-5.908)$ & $<0.0001$ \\
\hline $\begin{array}{l}\text { Cardiovascular } \\
\text { events II, ID vs. DD }\end{array}$ & $10.769(5.809-19.967)$ & $<0.0001$ & $14.792(7.552-28.974)$ & $<0.0001$ & $16.364(8.312-32.216)$ & $<0.0001$ & $15.001(7.612-29.564)$ & $<0.0001$ \\
\hline Stroke II, ID vs. DD & $0.535(0.193-1.483)$ & 0.2293 & $0.431(0.154-1.205)$ & 0.1084 & $0.438(0157-1.226)$ & 0.1159 & $0.435(0.155-1.219)$ & 0.1133 \\
\hline $\begin{array}{l}\text { Total mortality II, } \\
\text { ID vs. DD }\end{array}$ & $0.488(0.151-1.579)$ & 0.2311 & $0.443(0.135-1.459)$ & 0.1807 & $0.435(0.132-1.435)$ & 0.1718 & $0.443(0.135-1.458)$ & 0.1805 \\
\hline
\end{tabular}

Abbreviations: ACE-I, angiotensin-converting enzyme inhibitor; ARB, angiotensin II type 1 receptor blocker; CVD, cerebro-cardiovascular disease; DBP, diastolic blood pressure; DM, diabetes mellitus; DL, dyslipidemia; PWV, pulse wave velocity; SBP, systolic blood pressure.

${ }^{a}$ CVD risk factors: age, sex, smoking, SBP, DBP, PWV, DM and DL.

Table 3b Cox proportional hazard models for all patients

\begin{tabular}{|c|c|c|c|c|c|c|c|c|}
\hline & \multicolumn{2}{|l|}{$\begin{array}{c}\text { Model } 1 \\
\text { (not adjusted) }\end{array}$} & \multicolumn{2}{|c|}{$\begin{array}{c}\text { Model } 2 \text { (adjusted for } \\
\text { advanced CVD risk factors) }^{a}\end{array}$} & \multicolumn{2}{|c|}{$\begin{array}{l}\text { Model } 3 \text { (model } 2 \text { adjusted } \\
\text { for antihypertensive drugs) }\end{array}$} & \multicolumn{2}{|c|}{$\begin{array}{l}\text { Model } 4 \text { (model } 2 \text { adjusted } \\
\text { for } A C E-I \text { or/and } A R B \text { ) }\end{array}$} \\
\hline & $\operatorname{Exp}(95 \% \mathrm{Cl})$ & $P$ & $\operatorname{Exp}(95 \% \mathrm{Cl})$ & $P$ & $\operatorname{Exp}(95 \% \mathrm{Cl})$ & $\mathrm{P}$ & $\operatorname{Exp}(95 \% \mathrm{Cl})$ & $\mathrm{P}$ \\
\hline CVD II, ID vs. DD & $3.643(2.317-5.727)$ & $<0.0001$ & $2.879(1.725-4.804)$ & $<0.0001$ & $2.918(1.744-4.880)$ & $<0.0001$ & $3.513(2.160-5.712)$ & $<0.0001$ \\
\hline $\begin{array}{l}\text { Cardiovascular } \\
\text { events II, ID vs. DD }\end{array}$ & 10.769 (5.809-19.967) & $<0.0001$ & $13.994(6.685-29.292)$ & $<0.0001$ & $13.849(6.601-29.057)$ & $<0.0001$ & $14.254(6.740-30.145)$ & $<0.0001$ \\
\hline Stroke II, ID vs. DD & $0.535(0.193-1.483)$ & 0.2293 & $0.302(0.092-0.987)$ & 0.0476 & $0.311(0.095-1.019)$ & 0.0537 & $0.314(0.096-1.026)$ & 0.0552 \\
\hline Total mortality II, & $0.488(0.151-1.579)$ & 0.2311 & $0.748(0.377-1.483)$ & 0.4057 & $0.455(0.136-1.520)$ & 0.2007 & $0.436(0.132-1.443)$ & 0.1740 \\
\hline
\end{tabular}

Abbreviations: ACE-I, angiotensin-converting enzyme inhibitor; ARB, angiotensin II type 1 receptor blocker; CVD, cerebro-cardiovascular disease; DBP, diastolic blood pressure; DM, diabetes mellitus; DL, dyslipidemia; MI, myocardial infarction; PWV, pulse wave velocity; SBP, systolic blood pressure.

aAdvanced CVD risk factors: age, sex, smoking, SBP, DBP, PWV, DM, DL, previous MI or stroke and left ventricular hypertrophy.

Table 3c Cox proportional hazard models for patients aged $<65$ years

\begin{tabular}{|c|c|c|c|c|c|c|c|c|}
\hline & \multicolumn{2}{|c|}{$\begin{array}{c}\text { Model } 1 \\
\text { (not adjusted) }\end{array}$} & \multicolumn{2}{|c|}{$\begin{array}{l}\text { Model } 2 \text { (adjusted for } \\
\text { CVD risk factors) }\end{array}$} & \multicolumn{2}{|c|}{$\begin{array}{l}\text { Model } 3 \text { (model } 2 \text { adjusted } \\
\text { for antihypertensive drugs) }\end{array}$} & \multicolumn{2}{|c|}{$\begin{array}{l}\text { Model } 4 \text { (model } 2 \text { adjusted } \\
\quad \text { for } A C E-I \text { or/and } A R B \text { ) }\end{array}$} \\
\hline & $\operatorname{Exp}(95 \% \mathrm{Cl})$ & $P$ & $\operatorname{Exp}(95 \% \mathrm{Cl})$ & $P$ & $\operatorname{Exp}(95 \% \mathrm{Cl})$ & $P$ & $\operatorname{Exp}(95 \% \mathrm{Cl})$ & $P$ \\
\hline CVD II,ID vs. DD & 3.795 (2.209-6.519) & $<0.0001$ & 3.535 (1.949-6.412) & $<0.0001$ & 3.604 (1.981-6.559) & $<0.0001$ & 3.663 (1.993-6.733) & $<0.0001$ \\
\hline $\begin{array}{l}\text { Cardiovascular } \\
\text { events II, ID vs. DD }\end{array}$ & $14.818(6.775-32.411)$ & $<0.0001$ & $21.412(8.339-54.981)$ & $<0.0001$ & $21.844(8.427-56.620)$ & $<0.0001$ & $20.875(8.033-54.250)$ & $<0.0001$ \\
\hline Stroke II, ID vs. DD & $0.365(0.088-1.518)$ & 0.1658 & $0.329(0.076-1.425)$ & 0.1371 & $0.332(0.076-1.439)$ & 0.1404 & $0.331(0.076-1.442)$ & 0.1407 \\
\hline Total mortality II, & $0.252(0.034-1.861)$ & 0.1765 & $0.355(0.045-2.820)$ & 0.3275 & $0.335(0.042-2.695)$ & 0.3041 & $0.358(0.045-2.846)$ & 0.3313 \\
\hline
\end{tabular}

ID vs. DD

Abbreviations: ACE-I, angiotensin-converting enzyme inhibitor; ARB, angiotensin II type 1 receptor blocker; CVD, cerebro-cardiovascular disease; DBP, diastolic blood pressure; DM, diabetes mellitus; DL, dyslipidemia; PWV, pulse wave velocity; SBP, systolic blood pressure.

aCVD risk factors: age, sex, smoking, SBP, DBP, PWV, DM and DL.

Table 3d Cox proportional hazard models for patients aged $<65$ years

\begin{tabular}{|c|c|c|c|c|c|c|c|c|}
\hline & \multicolumn{2}{|c|}{$\begin{array}{c}\text { Model } 1 \\
\text { (not adjusted) }\end{array}$} & \multicolumn{2}{|c|}{$\begin{array}{c}\text { Model } 2 \text { (adjusted for } \\
\text { CVD risk factors) }\end{array}$} & \multicolumn{2}{|c|}{$\begin{array}{l}\text { Model } 3 \text { (model } 2 \text { adjusted } \\
\text { for antihypertensive drugs) }\end{array}$} & \multicolumn{2}{|c|}{$\begin{array}{l}\text { Model } 4 \text { (model } 2 \text { adjusted } \\
\quad \text { for } A C E \text {-I or/and } A R B \text { ) }\end{array}$} \\
\hline & $\operatorname{Exp}(95 \% \mathrm{Cl})$ & $\mathrm{P}$ & $\operatorname{Exp}(95 \% \mathrm{Cl})$ & $\mathrm{P}$ & $\operatorname{Exp}(95 \% \mathrm{Cl})$ & $\mathrm{P}$ & $\operatorname{Exp}(95 \% \mathrm{Cl})$ & $\mathrm{P}$ \\
\hline CVD II,ID vs. DD & 3.795 (2.209-6.519) & $<0.0001$ & 2.707 (1.404-5.219) & 0.0029 & $2.758(1.424-5.342)$ & 0.0026 & $2.731(1.396-5.344)$ & 0.0033 \\
\hline $\begin{array}{l}\text { Cardiovascular } \\
\text { events II, ID vs. DD }\end{array}$ & $14.818(6.775-32.411)$ & $<0.0001$ & $25.222(8.434-75.427)$ & $<0.0001$ & $25.966(8.428-79.996)$ & $<0.0001$ & 22.855 (7.438-70.225) & $<0.0001$ \\
\hline Stroke II, ID vs. DD & $0.365(0.088-1.518)$ & 0.1658 & $0.153(0.020-1.165)$ & 0.0699 & $0.160(0.021-1.223)$ & 0.0744 & $0.157(0.020-1.202)$ & 0.0746 \\
\hline Total mortality II, & $0.252(0.034-1.861)$ & 0.1765 & $0.333(0.040-2.751)$ & 0.3074 & $0.320(0.038-2.678)$ & 0.2929 & $0.333(0.040-2.755)$ & 0.3079 \\
\hline
\end{tabular}

ID vs. DD

Abbreviations: ACE-I, angiotensin-converting enzyme inhibitor; ARB, angiotensin II type 1 receptor blocker; CVD, cerebro-cardiovascular disease; DBP, diastolic blood pressure; DM, diabetes mellitus; DL, dyslipidemia; MI, myocardial infarction; PWV, pulse wave velocity; SBP, systolic blood pressure.

aCVD risk factors: age, sex, smoking, SBP, DBP, PWV, DM, DL, previous MI or stroke, PWV and left ventricular hypertrophy. 
In cross-sectional studies, the $A C E \mathrm{DD}$ genotype has functioned as a risk factor for CVD in Japan; ${ }^{10,19-22,23}$ we confirmed this risk in our cohort. Subjects with the DD genotype exhibited higher tissue ACE activity and increased ACE expression in the plaque of acute coronary syndrome, observations that may explain why hypertensive patients with the DD genotype have a higher incidence of cardiovascular disease. In contrast, in the GenHAT study, ${ }^{15}$ the ACE I/D genotype was not a predictor of CVD, nor did it modify the response to antihypertensive treatment. A major difference between the present cohort study and the GenHAT study is the race of the participants. It is well known that the genetic frequency of the ACE I/D polymorphism differs greatly between Caucasians and Asians, including Japanese. In the present study, the frequencies of the II/ID/DD polymorphisms were $40.2 / 47.4 / 12.4 \%$, respectively, and the allele frequencies of I/D were $63.9 / 36.1 \%$, respectively. In the GenHAT study, the frequencies of the II/ID/DD polymorphisms were $19.7 / 50.0 / 30.3 \%$, respectively, and the allele frequencies of I/D were $44.7 / 55.3 \%$, respectively. The inclusion criteria for these two cohort studies were also different; the GenHAT study recruited high-risk hypertensive patients with left ventricular hypertrophy and previous MI and stroke, whereas our study included both low- and high-risk hypertensive patients. To avoid heterogeneity in our study, we adjusted for coronary risk factors included in the GenHAT study, but the relationship between $A C E$ polymorphisms and cardiovascular events did not change. Another difference was that our study population was younger than that in the GenHAT study. We found that the DD genotype was associated with the occurrence of CVD in patients aged $<65$ years; as shown in a previous report, the effect of this polymorphism decreased with age. ${ }^{24}$

As we previously reported, the association between RAS inhibition and $A C E$ I/D polymorphism is very important. ${ }^{18}$ Although some studies have reported that administration of ACE-Is and/or ARBs vary the effect of the ACE I/D genotype on cardiovascular events, ${ }^{25}$ others have not. ${ }^{15}$ Although we only have baseline information about antihypertensive treatments, the ACE DD genotype was an independent risk factor for CVD after adjusting for ACE-I/ARB drugs and antihypertensive drugs. A previous report ${ }^{26}$ revealed an association between aldosterone escape and the DD genotype, suggesting an influence by aldosterone escape. Moreover, the DD genotype was an independent risk factor for CVD after adjusting for not only all, but also each antihypertensive drug or statins treatment (data not shown). In the present study, the $A C E$ polymorphism exerted a significant effect on stroke. It is thought that stroke is a blood pressure-dependent event, but in this study patient blood pressure was well controlled, with patients receiving medication that affects stroke occurrence. Although the ACE DD genotype was associated with a higher incidence of CVD, the M235T SNP of AGT and the A1166C SNP of $A T 1 R$ also exhibited small associations. In the present study, only the TT genotype of the M235T AGT SNP was associated with a lower event survival ratio compared with the MT+MM genotype. As the frequencies of the TT genotype in AGT and the CC genotype in AT1R are low in the general population, a larger cohort study would be required to confirm this association. However, this is the first report to demonstrate the possibility of a genetic risk of the M235T AGT SNP for CVD in hypertensive patients. Although this evidence is not directly reflective of common clinical practice, we propose to tailor treatment to the patient by genotyping patients with hypertension.

\section{Study limitations}

The present study had several limitations. First, this cohort study was a hospital-based single-center study rather than a multi-center study.
To avoid study bias and confirm the present observations, a larger cohort and multi-center trials are needed. Second, patients who enrolled in this study received many types of antihypertensive treatment, and some patients received agents that affected CVD. Recent reports indicate that treatment with ACE-Is, ARBs, or statins improves arterial stiffness, suggesting that treatment with these medications may contribute to better survival outcomes.

\section{ACKNOWLEDGEMENTS}

We thank Ms Kazuko Iwasa for her excellent technical assistance and Ms Eriko Nagata for her excellent administrative assistance. Grants: this study was funded by the Osaka Medical Research Foundation for Incurable Diseases.

1 Kearney PM, Whelton M, Reynolds K, Muntner P, Whelton PK, He J. Global burden of hypertension: analysis of worldwide data. Lancet 2005; 365: 217-223.

2 Ariyaratnam R, Casas JP, Whittaker J, Smeeth L, Hingorani AD, Sharma P. Genetics of ischaemic stroke among persons of non-European descent: a meta-analysis of eight genes involving approximately 32500 individuals. PLoS Med 2007; 4: e131.

3 Ohishi M, Ueda M, Rakugi H, Okamura A, Naruko T, Becker AE, Hiwada K, Kamitani A, Kamide K, Higaki J, Ogihara T. Upregulation of angiotensin-converting enzyme during the healing process after injury at the site of percutaneous transluminal coronary angioplasty in humans. Circulation 1997; 96: 3328-3337.

4 Wang JG, Staessen JA. Genetic polymorphisms in the renin-angiotensin system: relevance for susceptibility to cardiovascular disease. Eur J Pharmacol 2000; 410: 289-302.

5 Ohishi M, Ueda M, Rakugi H, Naruko T, Kojima A, Okamura A, Higaki J, Ogihara T. Enhanced expression of angiotensin-converting enzyme is associated with progression of coronary atherosclerosis in humans. J Hypertens 1997; 15: 1295-1302.

6 Jeunemaitre X, Soubrier F, Kotelevtsev YV, Lifton RP, Williams CS, Charru A, Hunt SC, Hopkins PN, Williams RR, Lalouel JM, Corvol P. Molecular basis of human hypertension: role of angiotensinogen. Cell 1992; 71: 169-180.

7 Danser AH, Schalekamp MA, Bax WA, van den Brink AM, Saxena PR, Riegger GA, Schunkert H. Angiotensin-converting enzyme in the human heart. Effect of the deletion/ insertion polymorphism. Circulation 1995; 92: 1387-1388.

8 Rigat B, Hubert C, Alhenc-Gelas F, Cambien F, Corvol P, Soubrier F. An insertion/ deletion polymorphism in the angiotensin I-converting enzyme gene accounting for half the variance of serum enzyme levels. J Clin Invest 1990; 86: 1343-1346.

9 Cambien F, Poirier O, Lecerf L, Evans A, Cambou JP, Arveiler D, Luc G, Bard JM, Bara L, Ricard $\mathrm{S}$ et al. Deletion polymorphism in the gene for angiotensin-converting enzyme is a potent risk factor for myocardial infarction. Nature 1992; 359: 641-644.

10 Ohishi M, Fujii K, Minamino T, Higaki J, Kamitani A, Rakugi H, Zhao Y, Mikami H, Miki T, Ogihara T. A potent genetic risk factor for restenosis. Nat Genet 1993; 5: 324-325.

11 Higaki J, Baba S, Katsuya T, Sato N, Ishikawa K, Mannami T, Ogata J, Ogihara T. Deletion allele of angiotensin-converting enzyme gene increases risk of essential hypertension in Japanese men: the Suita Study. Circulation 2000; 101: 2060-2065.

12 Nakata Y, Katsuya T, Rakugi H, Takami S, Sato N, Kamide K, Ohishi M, Miki T, Higaki J, Ogihara T. Polymorphism of angiotensin converting enzyme, angiotensinogen, and apolipoprotein $\mathrm{E}$ genes in a Japanese population with cerebrovascular disease. Am J Hypertens 1997; 10: 1391-1395.

13 Takami S, Imai Y, Katsuya T, Ohkubo T, Tsuji I, Nagai K, Satoh H, Hisamichi S, Higaki J, Ogihara T. Gene polymorphism of the renin-angiotensin system associates with risk for lacunar infarction. The Ohasama study. Am J Hypertens 2000; 13: 121-127.

14 Ishikawa K, Baba S, Katsuya T, Iwai N, Asai T, Fukuda M, Takiuchi S, Fu Y, Mannami T, Ogata J, Higaki J, Ogihara T. T+31C polymorphism of angiotensinogen gene and essential hypertension. Hypertension 2001; 37: 281-285.

15 Arnett DK, Davis BR, Ford CE, Boerwinkle E, Leiendecker-Foster C, Miller MB, Black H, Eckfeldt JH. Pharmacogenetic association of the angiotensin-converting enzyme insertion/deletion polymorphism on blood pressure and cardiovascular risk in relation to antihypertensive treatment: the Genetics of Hypertension-Associated Treatment (GenHAT) Study. Circulation 2005; 111: 3374-3383.

16 Terai M, Ohishi M, Ito N, Takagi T, Tatara Y, Kaibe M, Komai N, Rakugi H, Ogihara T. Comparison of arterial functional evaluations as a predictor of cardiovascular events in hypertensive patients: the Non-Invasive Atherosclerotic Evaluation in Hypertension (NOAH) Study. Hypertens Res 2008; 31: 1135-1145.

17 Akasaka H, Katsuya T, Saitoh S, Sugimoto K, Fu Y, Takagi S, Ohnishi H, Rakugi H, Ura N, Shimamoto K, Ogihara T. Effects of angiotensin II type 1 receptor gene polymorphisms on insulin resistance in a Japanese general population: the Tanno-Sobetsu Study. Hypertens Res 2006; 29: 961-967.

18 Okamura A, Ohishi M, Rakugi H, Katsuya T, Yanagitani Y, Takiuchi S, Taniyama Y, Moriguchi $\mathrm{K}$, Ito $\mathrm{H}$, Higashino $\mathrm{Y}$, Fujii $\mathrm{K}$, Higaki J, Ogihara $\mathrm{T}$. Pharmacogenetic analysis of the effect of angiotensin-converting enzyme inhibitor on restenosis after percutaneous transluminal coronary angioplasty. Angiology 1999; 50: 811-822.

19 Kamitani A, Rakugi H, Higaki J, Ohishi M, Shi SJ, Takami S, Nakata Y, Higashino Y, Fujii K, Mikami $\mathrm{H}$ et al. Enhanced predictability of myocardial infarction in Japanese by combined genotype analysis. Hypertension 1995; 25: 950-953. 
20 Ohishi M, Rakugi H, Higaki J, Miki T, Ogihara T. Angiotensin-converting-enzyme genotype and ischemic heart disease. N Engl J Med 1995; 333: 459; author reply 459-460.

21 Fujisawa T, Ikegami H, Shen GQ, Yamato E, Takekawa K, Nakagawa Y, Hamada Y, Ueda $H$, Rakugi H, Higaki J. Angiotensin I-converting enzyme gene polymorphism is associated with myocardial infarction, but not with retinopathy or nephropathy, in NIDDM. Diabetes Care 1995; 18: 983-985.

22 Zhao Y, Hishimori K, Higaki J, Kamitani A, Ohishi M. Significance of the deletion polymorphism of the angiotensin converting enzyme gene as a risk of myocardial infarction in Japanese. Hypertens Res 1994; 17: 3.

23 Fujisawa T, Ikegami H, Kawaguchi Y, Hamada Y, Ueda H, Shintani M, Fukuda M, Ogihara T. Meta-analysis of association of insertion/deletion polymorphism of angiotensin I-converting enzyme gene with diabetic nephropathy and retinopathy. Diabetologia 1998; 41: 47-53.

24 Morris BJ, Zee RY, Schrader AP. Different frequencies of angiotensin-converting enzyme genotypes in older hypertensive individuals. J Clin Invest 1994; 94: 1085-1089.

25 Kretowski A, McFann K, Hokanson JE, Maahs D, Kinney G, Snell-Bergeon JK, Wadwa RP, Eckel RH, Ogden L, Garg S, Li J, Cheng S, Erlich HA, Rewers M. Polymorphisms of the renin-angiotensin system genes predict progression of subclinical coronary atherosclerosis. Diabetes 2007; 56: 863-871.

26 Cicoira M, Zanolla L, Rossi A, Golia G, Franceschini L, Cabrini G, Bonizzato A, Graziani $M$, Anker SD, Coats AJ, Zardini P. Failure of aldosterone suppression despite angiotensin-converting enzyme (ACE) inhibitor administration in chronic heart failure is associated with ACE DD genotype. J Am Coll Cardiol 2001; 37: 1808-1812. 